\title{
From the Editor
}

JBAM strives to present interesting and rigorously researched topics impacting people and organizations, and to present readers with a variety of views on organizational life. This issue illustrates this commitment and presents research from intra-personal to industry-wide perspectives.

Beginning with a look inward, the first article entitled "Self-Awareness and the Evolution of Leaders: The Need for a Better Measure of Self-Awareness" by Ashley and ReiterPalmon explores self-awareness but with a focus on leadership and leadership development. The outcome of this work is a self-awareness scale developed across a three-part study. The second article, "Good Times to Hard Times: An Examination of Adult Learners' Enrollment from 2004-2010" by Kimmel, Gaylor, Grubbs, and Hayes examines economic factors, motivational factors and barriers to learning in both face-toface and online learning environments across two time periods. Several interesting findings emerged including a reported increase in adult students' desire to influence career opportunities through education over the two time periods.

The third article by Lawrence and Kacmar takes a unique view of leader-member exchange by focusing on potentially negative outcomes of high-quality leader-member relationships. The paper, "Leader-Member Exchange and Stress: The Mediating Role of Job Involvement and Role Conflict" presents findings related to leader-member exchange (LMX) relationship quality and stress showing that role conflict and job involvement mediate the relationship between LMX and stress. As explained by the authors, even individuals in high quality LMX relationships may experience stress through job involvement. The final article, "Southwest Effect" - Decisions and Effects of Low Cost Carriers" by Mertens and Vowles takes a more strategic view of organizations to examine low-cost strategies in the airline industry. The possible effects of low-cost strategies for some airlines and likely reasoning for attempting low-cost strategies are discussed

I hope that this issue of JBAM is found to be interesting and useful and welcome any comments you may have.

Sincerely,

Angela Young

JBAM Editor

Ayoung3@calstatela.edu 
Reproduced with permission of the copyright owner. Further reproduction prohibited without permission. 